This is not the final published version. Final version can be found at:

Lam D, Ancelin ML, Ritchie K, Saffery R, Ryan J. DNA methylation and genetic variation of the angiotensin converting enzyme (ACE) in depression. Psychoneuroendocrinology. 2018; Volume 88, February 2018, Pages 1-8. https://doi.org/10.1016/j.psyneuen.2017.11.003

https://www.sciencedirect.com/science/article/pii/S0306453017306212

Post-print version

\title{
DNA methylation and genetic variation of the angiotensin converting enzyme $(A C E)$ in depression
}

Dilys Lam ${ }^{1}$, BSc (Hons); Marie-Laure Ancelin ${ }^{2}, \mathrm{PhD}$; Karen Ritchie ${ }^{2,3}, \mathrm{PhD}$; Richard Saffery ${ }^{1}$, PhD; Joanne Ryan ${ }^{1,2,4, *}, \mathrm{PhD}$.

${ }^{1}$ Cancer \& Disease Epigenetics, Murdoch Children's Research Institute, Royal Children's Hospital \& Department of Paediatrics, University of Melbourne, Parkville, Victoria, Australia

${ }^{2}$ INSERM, U1061, Neuropsychiatrie, Recherche Clinique et Epidémiologique, Univ. Montpellier, Montpellier, France

${ }^{3}$ Centre for Clinical Brain Sciences, University of Edinburgh, Edinburgh, UK

${ }^{4}$ Department of Epidemiology and Preventive Medicine, Monash University, Melbourne, Victoria, Australia

*Corresponding author at: Department of Epidemiology and Preventive Medicine Monash University Level 5, The Alfred Centre 99 Commercial Road Melbourne VIC 3004 Australia. Tel.: +61 039903 0200. Email address: joanne.ryan@ monash.edu 


\begin{abstract}
BACKGROUND: Depression is one of the most prevalent psychiatric disorders, and in older persons is associated with high levels of comorbidity and under-treatment. Dysfunction of the hypothalamicpituitary-adrenal (HPA) stress axis is consistently observed in the older population as well as depressed patients, with the angiotensin converting enzyme $(A C E)$ a key regulator of the stress response. Epigenetic regulation of $A C E$ may play an important role in HPA axis (dys)regulation.

OBJECTIVE: To investigate $A C E$ promoter methylation as a biomarker of late-life depression, and its association with genetic variation and cortisol secretion.

METHOD: The longitudinal general population ESPRIT study is aimed at investigating psychiatric disorders in older persons $(n=1863$, average age $=73$ ). Depression was assessed using the Mini International Neuropsychiatric Interview according to DSM-IV criteria and the Centre for Epidemiologic Studies Depression Scale (CES-D). Genotype information for seven polymorphisms across the ACE gene was also available. Blood and saliva samples collected at baseline and used to extract DNA and measure cortisol, respectively. Sequenom MassARRAY was used to measure promoter DNA methylation of the $A C E$ gene (n=552).

RESULTS: There was no evidence of an association between ACE promoter methylation and depression. However, there was evidence that $A C E$ genetic variants influenced methylation, and modified the association between depression and methylation ( $\Delta$ at various sites; $-2.05 \%$ to $1.74 \% ; \mathrm{p}=$ 0.019 to 0.039$)$. Multivariate analyses were adjusted for participants' lifestyle, health and medical history. Independent of depression status, $A C E$ methylation was inversely correlated with cortisol levels $(\mathrm{r}=-0.336, \mathrm{p}=0.042)$.
\end{abstract}

CONCLUSION: This study provides evidence that associations between $A C E$ methylation and depression are genotype-dependent, suggesting that the development of reliable depression biomarkers may need to consider methylation levels in combination with underlying genetic variation. $A C E$ methylation may also be a suitable biomarker of cortisol and/or HPA axis activity.

\title{
Keywords
}

Angiotensin converting enzyme $(A C E)$; cortisol; depression; DNA methylation; epigenetics; genetic variation 


\section{Introduction}

Depression is one of the most prevalent psychiatric disorders, yet despite considerable advances in clinical practice, case detection remains relatively poor at all ages. In older persons, untreated depression has been furthermore associated with both high rates of functional impairment and comorbidity, notably cardiovascular disease (CVD) (Alexopoulos, 2005). One of the principal factors contributing to poor case identification is insufficient knowledge of the mechanisms underlying disease onset, and in particular the causes of variations in clinical presentation and treatment response. Development of specific biomarkers would significantly contribute to a better understanding of disease etiology and heterogeneity, as well as improving case detection and monitoring.

Growing evidence suggests that depression results from complex interactions between genetic and environmental factors (Caspi et al., 2003, Booij et al., 2013). Epigenetic mechanisms such as DNA methylation may play an important role due to their ability to respond to both genetic and environmental influences to potentiate changes in gene activity (Tsankova et al., 2007). Whilst depression is a brainbased disorder, the effects on an individual are more wide-spread, and physiological changes in peripheral tissues have been observed (O'Donovan et al., 2010, Thomson et al., 2014). Furthermore, brain tissue cannot be accessed in living humans, so human epigenetic marks have been predominantly studied in peripheral tissues including blood and buccal (mouth epithelial cells) (Lockwood et al., 2015), which offer an advantage of being easily accessible, thus contributing to their potential as biomarkers. Biomarkers do not always lie along causal pathways, but must robustly associate with the phenotype to ensure diagnostic utility.

The hypothalamic-pituitary-adrenal (HPA) axis is a neuroendocrine system that is central to regulating responses to stress (Palazidou, 2012). In older persons, a high dysfunction of the HPA axis is observed (Otte et al., 2005) which may be enhanced by stimulatory effects of genes involved in the axis, such as that coding for the angiotensin converting enzyme (ACE). ACE converts Angiotensin I into Angiotensin II to regulate cardiovascular homeostasis (Sayed-Tabatabaei et al., 2006). ACE also has a wellcharacterised role in regulating the HPA axis following stress-activation through stimulatory effects on two hormones, adrenocorticotropin hormone (ACTH) and corticotropin-releasing-hormone 
(CRH)(Armando et al., 2007, Pavlatou et al., 2008). Hyperactivity of the axis is observed consistently in depressed patients, as attested by elevated levels of cortisol, CRH and ACTH (Lloyd and Nemeroff, 2011). ACE is notably considered a candidate susceptibility factor for the bi-directional relationship between depression and CVD (Bondy, 2007). Genetic studies have linked several ACE genetic variants to an increased risk of depression (Baghai et al., 2006, Lopez-Leon et al., 2008, Ancelin et al., 2013) and to antidepressant treatment response (Baghai et al., 2001, Baghai et al., 2004). ACE polymorphisms have also been shown to regulate cortisol secretion, a measure of HPA axis activity(Baghai et al., 2002, Baghai et al., 2006, Ancelin et al., 2013).

To date, few studies have investigated DNA methylation of $A C E$ and its association with depression. This study used data gathered from a large population based cohort of older individuals to investigate the associations between depression status and methylation at the promoter region of the $A C E$ gene in peripheral blood. Analyses were adjusted for participants' lifestyle, health and medical history. Potential modifying effects of genetic variation across the $A C E$ gene and cortisol levels were also considered. 


\section{Methods}

\subsection{Study participants}

The ESPRIT study is a French longitudinal general population study assessing neuropsychiatric disorders in older individuals (Ritchie et al., 2004). Participants were recruited by random selection from electoral rolls within the Montpellier district, between 1999 and 2001. Non-institutionalised individuals aged 65 years and over were eligible and were contacted via mail with an invitation to participate, along with information detailing study procedures. The ESPRIT study protocol was approved by the regional ethics committee (Ethical Committee of University Hospital of KremlinBicêtre, France). Following recruitment, participants underwent standardised clinical assessments, as well as health and psychiatric interviews. Information was collected on the participants' lifestyle, present state of health, medical history, medication use and exposure to adverse environmental factors. All participants provided written informed consent.

\subsection{Depression assessment}

Current major depressive disorder (MDD) was diagnosed using a standardised psychiatric interview; the Mini International Neuropsychiatric Interview (MINI, French version 5.00), following the Diagnostic and Statistical Manual of Mental Disorders-IV (DSM-IV) (American Psychiatric Association, 1994). The MINI has been widely used in clinical and research settings, and validated within the general population setting (Sheehan et al., 1998). Participants that met the DSM-IV criteria for MDD were further reviewed by a panel of three psychiatrists and a psychologist with access to information from other health assessments. The Centre for Epidemiologic Studies-Depression (CES-D) scale was also administered to assess the severity of depressive symptoms (Radloff, 1977). This questionnaire has been previously validated in the older population (Radloff, 1977, Beekman et al., 1997). In contrast to the MINI, the CES-D scale is a self-reporting questionnaire, with a score of 16 or above considered the threshold for significant depressive symptoms warranting further clinical investigation(Radloff, 1977). To take into account that late-life depression covers a range of mild to severe depressive symptoms(Fiske et al., 2009), late-life depression assessment was based on two 
criteria; having a current diagnosis of MDD, or severe depressive symptoms (CES-D $\geq 16$ ), in keeping with prior work (Ancelin et al., 2013, Januar et al., 2015).

\subsection{Genotyping}

Of the 1863 recruited participants, 785 agreed to provide blood samples at baseline for research. Genomic DNA was extracted from white blood cells following a standard protocol(Ritchie et al., 2009), with samples stored at $-80^{\circ} \mathrm{C}$ until use. Genotyping was performed by LGC Genomics, Hoddesdon, UK using their KASP SNP genotyping system (Ancelin et al., 2013). This included data for seven single nucleotide polymorphisms (SNPs) across the ACE gene: $r s 1800764, r_{s} 4291, r s 4295, r s 4311, r s 4333$, $r s 4343, r s 4351$. These variants were chosen based on prior associations with depression and to ensure adequate coverage across the gene (Ancelin et al., 2013). The distribution of genotypes was examined using a chi-squared test for Hardy-Weinberg equilibrium. Linkage disequilibrium between the SNPs were also calculated, with relatively high linkage disequilibrium across 3 SNPs (rs1800764, rs4291, rs4295) as estimated by r2 values (>0.75) (Ancelin et al., 2013).

\subsection{ACE promoter methylation assay}

A 356 base pair (bp) assay (hg_38: chr17: 63476511-63476866) was designed using the Epidesigner package (epidesigner.com) to cover a region of the $A C E$ promoter $\mathrm{CpG}$ island, spanning $32 \mathrm{CpG}$ sites, where differential methylation of several CpG sites was previously reported (Figure S1) (Zill et al., 2012). Sodium bisulphite conversion of 500ng DNA from each participant blood sample was performed using the EZ-96 DNA Methylation-Lightning MagPrep Kit (Zymo Research; Irvine, USA) following the manufacturer's protocol. PCR amplification of the region of interest was performed in technical triplicates for all participant samples (Table S1), to account for possible variability (Coolen et al., 2007). The primers used were F: 5'-TAGAGGAAGTTGGAGAAAGGGTT-3' and R: 5'CCTACAAAACACCTAAAATCCCC-3', with an adapter (5'-aggaagagag) and T7 tag (5'cagtaatacgactcactatagggagaaggct) attached respectively. DNA methylation was quantified for each triplicate sample using the SEQUENOM MassARRAY EpiTYPER platform (Coolen et al., 2007). Mean methylation values were calculated from replicates within $10 \%$ of the median (Martino et al., 
2013). Further quality control included the exclusion of $\mathrm{CpG}$ units or participants where less than $50 \%$ of methylation data was available, to help ensure that spurious data was not analysed. Clearly outlying data points, i.e. those more than 3 times the interquartile range, were also excluded $(n=21)$. Following this quality control, data was obtained for $16 \mathrm{CpG}$ units encompassing $25 \mathrm{CpG}$ sites (Table S2, Figure S1).

\subsection{Cortisol measurement}

Salivary cortisol was collected from a subsample of participants not taking medications likely to affect cortisol levels(Ancelin et al., 2013) and measured by direct radioimmunoassay (Diagnostic systems Laboratories, Webster, TX, USA) (Hellhammer et al., 1987). Cortisol samples were obtained at four time points throughout the day. Participants were told to withhold from eating, drinking or smoking at least 30 minutes before saliva collection. Salivary samples were collected by participants carrying out normal daily activities at home at least 1 hour after awakening, and subsequently 3, 7 and 14 hours after the first sampling, with the exact time recorded as published previously (Beluche et al., 2009).

\subsection{Statistical analysis}

After quality control, $A C E$ methylation data was obtained for 552 participants, ranging from 414 to 550 at individual $\mathrm{CpG}$ units (Table S2). Participants excluded from our analysis ( $\mathrm{n}=233$ ) were not significantly different in key variables (Table 1) from those who were included. However, when compared with all recruited participants $(n=1863)$, those included in our analyses were more likely to be male, have hypertension and less likely to be taking anxiolytic medication $(\mathrm{p}<0.05)$. The raw mean methylation values were first log-transformed to normalise the data and these values were used for all subsequent parametric statistical tests. To avoid undefined log-transformed values, such as when raw mean methylation equals 0 , a value of 0.001 was added prior to log transformation. Univariate analysis (t-tests, chi-squared tests) were used to investigate potential associations between depression and methylation, as well as between population characteristics with depression and/or methylation levels independently. Multivariate linear regression analysis adjusted for potential confounding factors; population characteristics associated with both depression (shown in Table 1) and methylation at a 
conservative level of $\mathrm{p}<0.15$, namely sex, age, smoking, functional impairment, ischemic disease, diabetes, thyroid disease, comorbidities, impaired cognition, antidepressant use, and batch effects (from different Sequenom chips). Genetic variants were also considered as potential effect modifiers of the association between depression and DNA methylation, by including a multiplicative interaction term in the regression models. When evidence of potential effect modification was found $(\mathrm{p}<0.15)$, stratified analysis was then performed to determine the association between depression status and DNA methylation across different genotype groups. Sensitivity analysis excluding antidepressant use was also performed $(n=31)$, given that antidepressants may potentially mask depression status and influence methylation independently of depression (Menke and Binder, 2014). For the 79 participants with both cortisol and methylation data, associations between salivary cortisol and methylation levels were examined using Pearson's correlation tests. Cortisol area under the curve (AUC) was standardised and calculated between the absolute morning ( $1 \mathrm{hr}$ after awakening) and evening levels (14hrs after first sampling) for each subject by extrapolating values from the equation of the regression line as published previously (Beluche et al., 2009). Based on the number of non-depressed and depressed individuals, our study will have $>90 \%$ power to detect a methylation change of $0.3 \%$ with $1 \%$ standard deviation (2-sided $\alpha=0.05$ ). All statistical analyses were performed using the statistical software package Stata 14.1 (StataCorp, College Station, USA). 


\section{Results}

\subsection{Study Population}

Characteristics of participants of this current study according to depression status are shown in Table 1. Depressed individuals $(29.7 \%)$ were significantly more likely to be female, older, living alone, functionally impaired, have poorer health and take psychotropic or anticholinergic medication, as compared to non-depressed persons. Habitual smokers were less likely to be depressed.

\subsection{Association between depression and ACE methylation}

We first investigated the association between depression and methylation at the $A C E$ promoter. In unadjusted analysis, mean methylation across the assayed region was not significantly different $(\Delta=-$ $0.10 \%, 95 \% \mathrm{CI}:-0.23 ; 0.03 \%, \mathrm{p}=0.941)$ between non-depressed $(3.53 \%, 95 \% \mathrm{CI}: 3.45 ; 3.60 \%)$ and depressed individuals $(3.43 \%, 95 \%$ CI: 3.32;3.53\%). No significant differences in methylation were found at any individual $\mathrm{CpG}$ units (Figure 1, Table S3) and further adjustment for potential confounders including age, sex, and antidepressant use (see Methods) did not modify this pattern. Sensitivity analysis with the exclusion of antidepressant users $(n=31)$ did not alter the significance of the associations.

\subsection{Modification of the association between depression and methylation by ACE genotype}

As genetic variation is known to influence DNA methylation, seven polymorphisms across the $A C E$ gene ( $r s 1800764, r s 4291, r s 4295, r s 4311, r s 4333, r s 4343, r s 4351)$ were investigated. The genotype frequencies in non-depressed and depressed groups were in Hardy-Weinberg equilibrium ( $p>0.10$ for all SNPs) and two SNPs, $r s 4333$ and $r s 4351$, were significantly associated with depression (Table S4).

In the whole sample, there was some evidence that specific genetic variation influenced methylation at several CpG sites (Table 2): rs4291 was associated with methylation at CpG 10.11 .12 while $r s 4333$ was associated with methylation at CpG 28.29.30. Homozygous TT individuals had significantly lower methylation in both cases. 
In investigating the potential modifying effects of genetic variation, all seven SNPs were found to modify the association between depression and methylation at multiple CpGs. In particular, genotypes for four $A C E$ variants were found to significantly modify the association between depression and methylation at CpG 28.29.30 (the p-values for interaction terms were for each SNP; rs1800764, $\mathrm{p}=0.061 ; r s 4351, \mathrm{p}=0.036 ; r s 4295, \mathrm{p}=0.016 ; r s 4311, \mathrm{p}=0.016)$. Following stratification analysis according to genotype, depression associated with significantly lower methylation at $\mathrm{CpG} 28.29 .30$ (Figure 2), for these specific homozygote genotypes: $r s 1800764$ (TT, $\Delta=-1.57 \%, 95 \% \mathrm{CI}$ : -2.85 ; $0.29 \%, \mathrm{p}=0.037$, Figure 2a); $r s 4351(\mathrm{AA}, \Delta=-2.05 \%, 95 \% \mathrm{CI}:-3.65 ;-0.46 \%, \mathrm{p}=0.039$, Figure 2b); $r s 4295(\mathrm{CC}, \Delta=-1.52 \%, 95 \% \mathrm{CI}:-2.70 ;-0.34 \% \mathrm{p}=0.023$, Figure $2 \mathrm{c})$ and $r s 4311(\mathrm{CC}, \Delta=-2.02 \%$, 95\%CI: $-3.50 ;-0.54 \%, p=0.031$, Figure 2d). Genotype also modified the associations between depression and methylation at several other CpGs; CpG 4.5.6.7 (rs4291, p-values for interaction terms $=0.013), \mathrm{CpG} 14$ (rs4333, p=0.147), and CpG 17 ( $r s 4343, \mathrm{p}=0.146)$. However, in these cases a positive association was observed, with significant higher methylation levels in the depressed individuals with these homozygote genotypes of $r s 4291$ (TT, $\Delta=0.59 \%, 95 \% \mathrm{CI}:-0.02 ; 1.20 \%$, p=0.019, Figure 2e) at CpG 4.5.6.7; $r s 4333$ (CC, $\Delta=1.74 \%, 95 \% \mathrm{CI}: 0.14 ; 3.35 \%$, $\mathrm{p}=0.033$, Figure $2 \mathbf{f}$ ) at $\mathrm{CpG} 14$; and $r s 4343$ (AA, $\Delta 0.74 \%, 95 \%$ CI: $0.073 ; 1.40 \%, \mathrm{p}=0.020$, Figure $2 \mathrm{~g}$ ) at $\mathrm{CpG} 17$. All associations, with the exception of $\mathrm{CpG}$ 14, remained significant following adjustment for potential confounders.

\subsection{Association between salivary cortisol levels and ACE methylation}

Finally, as the $A C E$ gene is involved in the regulation of cortisol secretion, the association between DNA methylation and AUC cortisol levels was examined, for a sub-sample of 79 participants (as detailed in the Methods). Baseline cortisol significantly negatively correlated with average methylation levels $(\mathrm{r}=-0.336, \mathrm{p}=0.042)$ (Figure 3) and methylation at $\mathrm{CpG} 1(\mathrm{r}=-0.247, \mathrm{p}=0.039)$. Given the small numbers in this sub-sample $(\mathrm{n}=79)$, we were unable to investigate whether these associations differed by depression status. However, when excluding the 14 depressed individuals in sensitivity analysis, only the association between average methylation (but not $\mathrm{CpG}$ 1) and basal cortisol levels remained significant $(\mathrm{r}=-0.417, \mathrm{p}=0.030, \mathrm{n}=65)$. 


\section{Discussion}

No significant association between depression status and $A C E$ promoter methylation in isolation was found in this older population of 552 individuals after adjustment for a wide range of potential confounding factors. However, there was evidence that $A C E$ genetic variants were associated with methylation, and modified the association between depression and methylation. In particular, depression was associated with significantly decreased $A C E$ methylation at $\mathrm{CpG} 28.29 .30$ for four variants, and significantly increased $A C E$ methylation at CpGs 1,14 and 17 for three variants. These novel findings were not confounded by sex, age, antidepressant use or other factors examined, including vascular disorder. Furthermore, in a small sub-sample, we provide some preliminary support that lower ACE methylation was correlated with higher cortisol levels, independent of depression status.

Previous studies have suggested the ACE gene to be implicated in depression onset (Baghai et al., 2006, Lopez-Leon et al., 2008, Ancelin et al., 2013), antidepressant response (Baghai et al., 2001, Baghai et al., 2004) and cortisol signaling (Baghai et al., 2002, Baghai et al., 2006, Ancelin et al., 2013). However, only one prior study has investigated $A C E$ promoter methylation in the context of depression (Zill et al., 2012). In a case-control study, Zill et al. (2012) analysed methylation in peripheral white blood cells, targeting a similar region of the $A C E$ promoter to that examined in our study. In contrast to our findings however, they reported an overall pattern of hypermethylation of the $A C E$ promoter in 81 MDD-diagnosed individuals compared to 81 non-depressed adults. They observed significant associations at 3 of $24 \mathrm{CpG}$ sites examined, corresponding to $\mathrm{CpG} 14,19-23$ and 24.25 in our study. We also observed hypermethylation at $\mathrm{CpG} 14$ in depressed participants, however with specific genotypes (see below). It should be noted that CpG 19-23 and 24.25 were not included in any of our analyses (failing initial quality control-see Methods) and CpG 28.29.30 was not examined in their study. Additionally, the average methylation levels at each $\mathrm{CpG}$ in our study appeared to be consistently lower (ranging from 0-9\%) than that observed by Zill et al. (2012) (up to 16\%).

Our study, like that of Zill et al. (2012) included European Caucasians, although their population was much smaller ( $\mathrm{n}=162)$ and more heterogeneous (19-72 years). Further, potential confounding or effect modification by other health, lifestyle or genetic factors was not considered. These differences may 
account for the divergent findings. Methylation levels change with age (the "epigenetic clock"), with reports of global hypomethylation (Johnson et al., 2012) and gene-specific hypermethylation with increasing age (Jung and Pfeifer, 2015), hence decreases in $A C E$ methylation may be specifically associated with late-life depression. Furthermore, increased dysfunction of the HPA axis has been observed in older individuals (Otte et al., 2005), which may be differentially influenced by ACE. Zill et al. (2012) also focused on patients diagnosed with MDD, which represents only 4.3\% ( $\mathrm{n}=16)$ of our study population. The majority of our study participants had severe depressive symptoms (as assessed with the CES-D), which may differ to clinically diagnosed MDD in its causation and associated physiological processes (Fiske et al., 2009, Fournier et al., 2010).

To our knowledge, this is the first study to show that $A C E$ promoter methylation was significantly negatively correlated with basal cortisol levels. Although in only a small sub-sample of participants, it is interesting to note that the direction of these associations supports the main findings of our study: decreased methylation was observed in depressed individuals (with specific genotypes) and was associated with heightened basal cortisol levels. An over-activation of cortisol signalling is frequently reported as a feature of depression (Lloyd and Nemeroff, 2011). Cortisol secretion has also previously been shown to be modulated by ACE polymorphisms (Baghai et al., 2006, Ancelin et al., 2013, Baghai et al., 2002). Our findings are in line with previous research demonstrating potential functional consequences of methylation at this region, with promoter methylation inversely correlated with $A C E$ expression and serum concentration in a dose-dependent manner (Riviere et al., 2011, Zill et al., 2012). Peripheral methylation levels have also been observed to be comparable to levels in post-mortem cortex and hippocampal tissues, which are part of a network that is regulated by the HPA axis and dysregulated in depressive disorders (Zill et al., 2012). Therefore, peripheral ACE methylation could be correlated with HPA axis activity, as measured by cortisol secretion. This suggests that $A C E$ methylation may be more suited as a biomarker for cortisol levels and/or HPA axis activity than for depression. However, no definitive conclusions can be drawn from this result, with further research needed, particularly considering the potential role of cortisol in depression (Herbert, 2013). 
Also unique to our study is the inclusion of six $A C E$ polymorphisms shown to be independently associated with methylation levels at several $\mathrm{CpGs}$ within the $A C E$ promoter. Such genetic variants that influence DNA methylation at specific sites are referred to as methylation quantitative trait loci or mQTLs. This fits with emerging literature highlighting the importance of the genome in regulating the epigenome (Gaunt et al., 2016). The effects of mQTLs tend to be more pronounced at CpG sites in close proximity (cis effect) with a distance of less than 1 Megabase (MB), although some act more distally (trans effect) (Zhang et al., 2010). The studied polymorphisms may be acting in cis on specific CpGs, as our promoter (rs1800764, rs4291) and intronic SNPs (rs4295, rs4311, rs4333, rs4343, rs4351) are within a distance of $13 \mathrm{~kb}$ from the promoter. Further studies are now needed to investigate the functionality of this putative layer of regulation.

An interesting finding from our study was that all seven polymorphisms investigated significantly modified the association between methylation and depression at several $\mathrm{CpG}$ units. This suggests that an effective biomarker would need to be a combination of $A C E$ methylation and genetic variants. For example, lower methylation levels at CpG 28.29.30 were associated with depression for four variants, but only in individuals homozygous for the T allele of $r s 1800764$, the A allele of $r s 4351$, or the $\mathrm{C}$ allele of $r s 4295$ or $r s 4311$. On the other hand, $A C E$ methylation levels at $\mathrm{CpG} 4.5 .6 .7,14$, and 17 were higher in depressed individuals, but only for those homozygous for T allele of $r s 4291$, the C allele of $r s 4333$, or the A allele of $r s 4343$ genotypes. In modulating susceptibility to diseases, genetic variants may modify the probability of DNA methylation and in turn regulate gene expression (Rakyan et al., 2011) and/or combine to modify depression risk (Zhi et al., 2013). While these findings add to the growing body of research in this field, further investigation is needed to clarify these complex genotype and sitespecific methylation interactions of studied polymorphisms and their functional consequences.

The major strength of this study is the large sample size which increases the statistical power to detect the likely subtle differences in peripheral methylation observed in psychiatric disorders (Olsson et al., 2010). Larger studies help provide more robust estimates of true associations, as small underpowered studies are prone to false positives, or type 1 errors (Ioannidis, 2005). Another strength of our study is the simultaneous investigation of both $A C E$ promoter methylation and genetic variation, and their 
association with depression. Other strengths of our study include the diagnosis of depression which was based on a clinical assessment (MINI, DSM-IV) of MDD, as well as a validated questionnaire of severe depressive symptoms (CES-D $\geq 16)$.

This study was conducted on an older French Caucasian population and while applying validated assessments, did not take into account age at onset of first depressive disorder. The extent to which these results can be applied to earlier onset depression with possible different etiologies in younger age groups remains to be determined (Blazer, 2003). DNA methylation patterns vary with age and ethnicity (Zhang et al., 2011, Johnson et al., 2012). The association between methylation and depression can be confounded by many lifestyle and health factors that affect methylation and depression status and we controlled for these in our analysis, however further analysis is still needed. Of particular importance are functional impairment, a characteristic of depressive disorders as listed in the DSM criteria (American Psychiatric Association, 1994); antidepressant use, which has been shown to modify methylation levels (Menke and Binder, 2014); and ACE inhibitors, which may have antidepressant-life effects (Vuckovic et al., 1991). Given our cross-sectional analysis, our findings may result from an association with one or more of these confounding factors. While the present study was able to consider a much wider range of potential confounders than the previous study, the potential for residual confounding from factors where information was not available or collected, remains possible. For example, factors known to influence DNA methylation include stress (beyond the cortisol marker) (Booij et al., 2013), methyl donors and nutrition (Anderson et al., 2012). There may also be unknown factors that influence DNA methylation and/or depression that have yet to be determined.

Finally, no adjustment for multiple testing was made, and none of the associations would remain significant at the stringent Bonferroni corrected $\mathrm{p}$ value of 0.00045 (accounting for $16 \mathrm{CpG}$ units and 7 SNPs, thus 112). However, such an adjustment would be overly conservative, as Bonferroni correction assumes independence of tests, and the tests we performed were not independent. Three of the SNPs for example, are in high linkage disequilibrium as stated in the text (page 7, section 2.3) and methylation levels at all but one of the $\mathrm{CpG}$ units was significantly correlated with other $\mathrm{CpG}$ units $(\mathrm{p}<0.05)$. 
Our study focuses on examining potential peripheral biomarkers of depression. Depression is a brainbased disorder, however it is becoming increasingly recognised as a systemic disease, with physiological changes observed in peripheral tissue (O'Donovan et al., 2010, Thomson et al., 2014). DNA methylation levels between blood and post-mortem brain tissues may be correlated, at least for some genes (Horvath et al., 2012). Furthermore, to be a useful peripheral biomarker, blood methylation levels do not need to reflect brain methylation levels or underlying mechanisms of depression, as long as they can be shown to be able to consistently distinguish depressed from non-depressed individuals across multiple independent studies.

Another limitation of our study is the candidate gene approach although there is evidence for the involvement of $A C E$ in depression. This candidate approach requires a strong a priori hypothesis, and being a complex disorder, may however, only have captured a small part of depression pathogenesis. For example, $A C E$ levels or methylation may only be relevant to manifestations of depression that involve dysregulation of the HPA axis. Epigenome-wide association studies (EWAS) could be an alternative approach, enabling interrogation of large proportions of genomic locations without an a priori hypothesis. EWAS studies have the added advantage of being able to adjust for cellular heterogeneity through computational estimation of cell composition, which may have distinct methylation profiles (Jaffe and Irizarry, 2014). This was not achievable in our study, potentially confounding our methylation analyses and may account for the lack of associations observed between depression and $A C E$ methylation. Unfortunately costs remain very high for large cohort EWAS studies such as our study cohort (Rakyan et al., 2011).

\section{Conclusion}

Our study of late-life depression provides evidence of genotype-specific associations between depression and $A C E$ methylation, as well as inverse correlations between $A C E$ methylation and cortisol secretion. These findings highlight the potential need to consider methylation levels in combination with genetic variation in the development of effective depression biomarkers. Given this novel finding, the small effect sizes observed and the potential relationship between age and DNA methylation patterns, replication in large independent populations are needed to confirm these findings. Extending 
methylation analysis to cover the entire gene and associated regulatory regions, and to other potential HPA axis genes should be considered. Importantly, future investigation of the mechanisms behind the genomic control of the epigenome in $A C E$ need to be undertaken.

\section{Conflict of interest}

All authors declare no conflicts of interest.

\section{Acknowledgments}

We thank all of the participants, and Dr Benjamin Ong for assistance with the Sequenom MassARRAY platform. The ESPRIT project is financed by the regional government of Languedoc-Roussillon, the Agence Nationale de la Recherche Project 07 LVIE 004, and an unconditional grant from Norvartis. This work was also supported by the National Health and Medical Research Council, through a Senior Research Fellowship (APP1045161 to RS); the Murdoch Children's Research Institute (studentship to DL); the Victorian Government's Operational Infrastructure Support Program. The funders had no role in the design and conduct of the study, in data collection, management, analysis or interpretation of the data and were not involved with the writing, preparation, review or approval of the manuscript. 
References

Alexopoulos, G.S. 2005. Depression in the elderly. Lancet. 365, 1961-70.

American Psychiatric Association, 1994. Diagnostic and Statistical Manual of Mental Disorders 4th edition. Washington, DC.

Ancelin, M.L., Carriere, I., Scali, J., Ritchie, K., Chaudieu, I. \& Ryan, J. 2013. Angiotensin-converting enzyme gene variants are associated with both cortisol secretion and late-life depression. Transl Psychiatry. 3, e322.

Anderson, O.S., Sant, K.E. \& Dolinoy, D.C. 2012. Nutrition and epigenetics: an interplay of dietary methyl donors, one-carbon metabolism and DNA methylation. J Nutr Biochem. 23, 853-9.

Armando, I., Volpi, S., Aguilera, G. \& Saavedra, J.M. 2007. Angiotensin II AT1 receptor blockade prevents the hypothalamic corticotropin-releasing factor response to isolation stress. Brain Res. $1142,92-9$.

Baghai, T.C., Binder, E.B., Schule, C., Salyakina, D., Eser, D., Lucae, S., Zwanzger, P., Haberger, C., Zill, P., Ising, M., Deiml, T., Uhr, M., Illig, T., Wichmann, H.E., Modell, S., Nothdurfter, C., Holsboer, F., Muller-Myhsok, B., Moller, H.J., Rupprecht, R. \& Bondy, B. 2006. Polymorphisms in the angiotensin-converting enzyme gene are associated with unipolar depression, ACE activity and hypercortisolism. Mol Psychiatry. 11, 1003-15.

Baghai, T.C., Schule, C., Zill, P., Deiml, T., Eser, D., Zwanzger, P., Ella, R., Rupprecht, R. \& Bondy, B. 2004. The angiotensin I converting enzyme insertion/deletion polymorphism influences therapeutic outcome in major depressed women, but not in men. Neurosci Lett. 363, 38-42.

Baghai, T.C., Schule, C., Zwanzger, P., Minov, C., Schwarz, M.J., de Jonge, S., Rupprecht, R. \& Bondy, B. 2001. Possible influence of the insertion/deletion polymorphism in the angiotensin Iconverting enzyme gene on therapeutic outcome in affective disorders. Mol Psychiatry. 6, 2589.

Baghai, T.C., Schule, C., Zwanzger, P., Minov, C., Zill, P., Ella, R., Eser, D., Oezer, S., Bondy, B. \& Rupprecht, R. 2002. Hypothalamic-pituitary-adrenocortical axis dysregulation in patients with major depression is influenced by the insertion/deletion polymorphism in the angiotensin Iconverting enzyme gene. Neurosci Lett. 328, 299-303.

Beekman, A.T., Deeg, D.J., Van Limbeek, J., Braam, A.W., De Vries, M.Z. \& Van Tilburg, W. 1997. Criterion validity of the Center for Epidemiologic Studies Depression scale (CES-D): results from a community-based sample of older subjects in The Netherlands. Psychol Med. 27, 2315.

Beluche, I., Chaudieu, I., Norton, J., Carriere, I., Boulenger, J.P., Ritchie, K. \& Ancelin, M.L. 2009. Persistence of abnormal cortisol levels in elderly persons after recovery from major depression. J Psychiatr Res. 43, 777-83.

Blazer, D.G. 2003. Depression in late life: review and commentary. J Gerontol A Biol Sci Med Sci. 58, 249-65.

Bondy, B. 2007. Common genetic factors for depression and cardiovascular disease. Dialogues Clin Neurosci. 9, 19-28.

Booij, L., Wang, D., Levesque, M.L., Tremblay, R.E. \& Szyf, M. 2013. Looking beyond the DNA sequence: the relevance of DNA methylation processes for the stress-diathesis model of depression. Philos Trans R Soc Lond B Biol Sci. 368, 20120251.

Caspi, A., Sugden, K., Moffitt, T.E., Taylor, A., Craig, I.W., Harrington, H., McClay, J., Mill, J., Martin, J., Braithwaite, A. \& Poulton, R. 2003. Influence of life stress on depression: moderation by a polymorphism in the 5-HTT gene. Science. 301, 386-9.

Coolen, M.W., Statham, A.L., Gardiner-Garden, M. \& Clark, S.J. 2007. Genomic profiling of CpG methylation and allelic specificity using quantitative high-throughput mass spectrometry: critical evaluation and improvements. Nucleic Acids Res. 35, e119.

Fiske, A., Wetherell, J.L. \& Gatz, M. 2009. Depression in older adults. Annu Rev Clin Psychol. 5, 36389.

Fournier, J.C., DeRubeis, R.J., Hollon, S.D., Dimidjian, S., Amsterdam, J.D., Shelton, R.C. \& Fawcett, J. 2010. Antidepressant drug effects and depression severity: a patient-level meta-analysis. JAMA. 303, 47-53. 
Gaunt, T.R., Shihab, H.A., Hemani, G., Min, J.L., Woodward, G., Lyttleton, O., Zheng, J., Duggirala, A., McArdle, W.L., Ho, K., Ring, S.M., Evans, D.M., Davey Smith, G. \& Relton, C.L. 2016. Systematic identification of genetic influences on methylation across the human life course. Genome Biol. 17, 61.

Hellhammer, D., C., K. \& L., B. 1987. Measurement of salivary cortisol under psychological stimulation. Advanced Methods in Psychobiology. 281-289.

Herbert, J. 2013. Cortisol and depression: three questions for psychiatry. Psychol Med. 43, 449-69.

Horvath, S., Zhang, Y., Langfelder, P., Kahn, R.S., Boks, M.P., van Eijk, K., van den Berg, L.H. \& Ophoff, R.A. 2012. Aging effects on DNA methylation modules in human brain and blood tissue. Genome Biol. 13, R97.

Ioannidis, J.P. 2005. Why most published research findings are false. PLoS Med. 2, e124.

Jaffe, A.E. \& Irizarry, R.A. 2014. Accounting for cellular heterogeneity is critical in epigenome-wide association studies. Genome Biol. 15, R31.

Januar, V., Ancelin, M.L., Ritchie, K., Saffery, R. \& Ryan, J. 2015. BDNF promoter methylation and genetic variation in late-life depression. Transl Psychiatry. 5, e619.

Johnson, A.A., Akman, K., Calimport, S.R., Wuttke, D., Stolzing, A. \& de Magalhaes, J.P. 2012. The role of DNA methylation in aging, rejuvenation, and age-related disease. Rejuvenation Res. 15, 483-94.

Jung, M. \& Pfeifer, G.P. 2015. Aging and DNA methylation. BMC Biol. 13, 7.

Lloyd, R.B. \& Nemeroff, C.B. 2011. The role of corticotropin-releasing hormone in the pathophysiology of depression: therapeutic implications. Curr Top Med Chem. 11, 609-17.

Lockwood, L.E., Su, S. \& Youssef, N.A. 2015. The role of epigenetics in depression and suicide: A platform for gene-environment interactions. Psychiatry Res. 228, 235-42.

Lopez-Leon, S., Janssens, A.C., Gonzalez-Zuloeta Ladd, A.M., Del-Favero, J., Claes, S.J., Oostra, B.A. \& van Duijn, C.M. 2008. Meta-analyses of genetic studies on major depressive disorder. Mol Psychiatry. 13, 772-85.

Martino, D., Loke, Y.J., Gordon, L., Ollikainen, M., Cruickshank, M.N., Saffery, R. \& Craig, J.M. 2013. Longitudinal, genome-scale analysis of DNA methylation in twins from birth to 18 months of age reveals rapid epigenetic change in early life and pair-specific effects of discordance. Genome Biol. 14, R42.

Menke, A. \& Binder, E.B. 2014. Epigenetic alterations in depression and antidepressant treatment. Dialogues Clin Neurosci. 16, 395-404.

O'Donovan, A., Hughes, B.M., Slavich, G.M., Lynch, L., Cronin, M.T., O'Farrelly, C. \& Malone, K.M. 2010. Clinical anxiety, cortisol and interleukin-6: evidence for specificity in emotion-biology relationships. Brain Behav Immun. 24, 1074-7.

Olsson, C.A., Foley, D.L., Parkinson-Bates, M., Byrnes, G., McKenzie, M., Patton, G.C., Morley, R., Anney, R.J., Craig, J.M. \& Saffery, R. 2010. Prospects for epigenetic research within cohort studies of psychological disorder: a pilot investigation of a peripheral cell marker of epigenetic risk for depression. Biol Psychol. 83, 159-65.

Otte, C., Hart, S., Neylan, T.C., Marmar, C.R., Yaffe, K. \& Mohr, D.C. 2005. A meta-analysis of cortisol response to challenge in human aging: importance of gender. Psychoneuroendocrinology. 30, 80-91.

Palazidou, E. 2012. The neurobiology of depression. Br Med Bull. 101, 127-45.

Pavlatou, M.G., Mastorakos, G., Lekakis, I., Liatis, S., Vamvakou, G., Zoumakis, E., Papassotiriou, I., Rabavilas, A.D., Katsilambros, N. \& Chrousos, G.P. 2008. Chronic administration of an angiotensin II receptor antagonist resets the hypothalamic-pituitary-adrenal (HPA) axis and improves the affect of patients with diabetes mellitus type 2: preliminary results. Stress. 11, 6272.

Radloff, L.S. 1977. The CES-D Scale: A Self-Report Depression Scale for Research in the General Population. Applied Psychological Measurement. 1, 385-401.

Rakyan, V.K., Down, T.A., Balding, D.J. \& Beck, S. 2011. Epigenome-wide association studies for common human diseases. Nat Rev Genet. 12, 529-41.

Ritchie, K., Artero, S., Beluche, I., Ancelin, M.L., Mann, A., Dupuy, A.M., Malafosse, A. \& Boulenger, J.P. 2004. Prevalence of DSM-IV psychiatric disorder in the French elderly population. Br J Psychiatry. 184, 147-52. 
Ritchie, K., Jaussent, I., Stewart, R., Dupuy, A.M., Courtet, P., Ancelin, M.L. \& Malafosse, A. 2009. Association of adverse childhood environment and 5-HTTLPR Genotype with late-life depression. J Clin Psychiatry. 70, 1281-8.

Riviere, G., Lienhard, D., Andrieu, T., Vieau, D., Frey, B.M. \& Frey, F.J. 2011. Epigenetic regulation of somatic angiotensin-converting enzyme by DNA methylation and histone acetylation. Epigenetics. 6, 478-89.

Sayed-Tabatabaei, F.A., Oostra, B.A., Isaacs, A., van Duijn, C.M. \& Witteman, J.C. 2006. ACE polymorphisms. Circ Res. 98, 1123-33.

Sheehan, D.V., Lecrubier, Y., Sheehan, K.H., Amorim, P., Janavs, J., Weiller, E., Hergueta, T., Baker, R. \& Dunbar, G.C. 1998. The Mini-International Neuropsychiatric Interview (M.I.N.I.): the development and validation of a structured diagnostic psychiatric interview for DSM-IV and ICD-10. J Clin Psychiatry. 59 Suppl 20, 22-33;quiz 34-57.

Thomson, C.A., McColl, A., Cavanagh, J. \& Graham, G.J. 2014. Peripheral inflammation is associated with remote global gene expression changes in the brain. J Neuroinflammation. 11, 73.

Tsankova, N., Renthal, W., Kumar, A. \& Nestler, E.J. 2007. Epigenetic regulation in psychiatric disorders. Nat Rev Neurosci. 8, 355-67.

Vuckovic, A., Cohen, B.M. \& Zubenko, G.S. 1991. The use of captopril in treatment-resistant depression: an open trial. J Clin Psychopharmacol. 11, 395-6.

Zhang, D., Cheng, L., Badner, J.A., Chen, C., Chen, Q., Luo, W., Craig, D.W., Redman, M., Gershon, E.S. \& Liu, C. 2010. Genetic control of individual differences in gene-specific methylation in human brain. Am J Hum Genet. 86, 411-9.

Zhang, F.F., Cardarelli, R., Carroll, J., Fulda, K.G., Kaur, M., Gonzalez, K., Vishwanatha, J.K., Santella, R.M. \& Morabia, A. 2011. Significant differences in global genomic DNA methylation by gender and race/ethnicity in peripheral blood. Epigenetics. 6, 623-9.

Zhi, D., Aslibekyan, S., Irvin, M.R., Claas, S.A., Borecki, I.B., Ordovas, J.M., Absher, D.M. \& Arnett, D.K. 2013. SNPs located at CpG sites modulate genome-epigenome interaction. Epigenetics. 8, 802-6.

Zill, P., Baghai, T.C., Schule, C., Born, C., Frustuck, C., Buttner, A., Eisenmenger, W., VaralloBedarida, G., Rupprecht, R., Moller, H.J. \& Bondy, B. 2012. DNA methylation analysis of the angiotensin converting enzyme (ACE) gene in major depression. PLoS One. 7, e40479. 
Table 1. Characteristics of study participants according to depression status at baseline

\begin{tabular}{|c|c|c|c|}
\hline Characteristics $^{\mathrm{a}}$ & No Depression & Depression & $p$-value $^{\mathrm{h}}$ \\
\hline$n$ & 388 & 164 & - \\
\hline Proportion of women (\%) & 48.5 & 68.9 & $<0.001$ \\
\hline Age (Mean \pm S.D. $)$ & $72.7 \pm 5.7$ & $74.0 \pm 5.4$ & 0.019 \\
\hline Lifestyle factors & & \multicolumn{2}{|c|}{ Proportion (\%) } \\
\hline $\begin{array}{l}\text { High education level }^{\mathrm{b}} \\
\text { Living alone } \\
\text { Habitual alcohol drinkers }(>24 \mathrm{~g} \text { per day) } \\
\text { Habitual smokers ( } \geq 10 \text { pack years) } \\
\text { Functional impairment }^{\mathrm{c}}\end{array}$ & $\begin{array}{l}33.5 \\
19.1 \\
21.2 \\
46.0 \\
5.15\end{array}$ & $\begin{array}{l}26.2 \\
36.6 \\
19.7 \\
33.8 \\
11.0\end{array}$ & $\begin{array}{l}0.092 \\
<0.001 \\
0.704 \\
0.009 \\
0.014\end{array}$ \\
\hline \multicolumn{4}{|l|}{ Health } \\
\hline 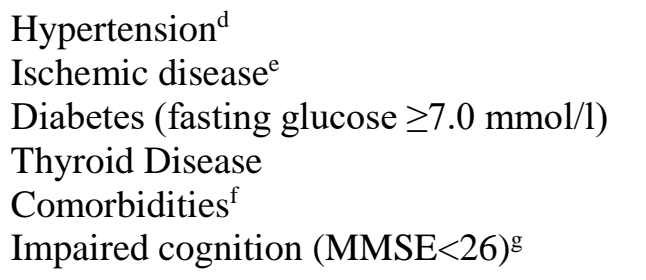 & $\begin{array}{l}54.9 \\
14.9 \\
9.30 \\
5.70 \\
16.7 \\
10.1\end{array}$ & $\begin{array}{l}54.3 \\
20.7 \\
14.6 \\
11.0 \\
26.8 \\
15.2\end{array}$ & $\begin{array}{l}0.892 \\
0.096 \\
0.066 \\
0.028 \\
0.007 \\
0.087\end{array}$ \\
\hline \multicolumn{4}{|l|}{ Medication } \\
\hline $\begin{array}{l}\text { Antidepressants } \\
\text { Anxiolytics } \\
\text { Psychotropic drugs } \\
\text { Anticholinergics }\end{array}$ & $\begin{array}{l}3.09 \\
5.67 \\
4.64 \\
4.38\end{array}$ & $\begin{array}{l}11.6 \\
13.4 \\
10.4 \\
9.76\end{array}$ & $\begin{array}{l}<0.001 \\
0.002 \\
0.012 \\
0.015\end{array}$ \\
\hline $\begin{array}{l}\text { Antihypertensive drugs } \\
\text { None } \\
\text { ACE inhibitor }\end{array}$ & $\begin{array}{l}54.9 \\
20.9\end{array}$ & $\begin{array}{l}50.6 \\
26.2\end{array}$ & $\begin{array}{l}- \\
0.176\end{array}$ \\
\hline Other & 24.2 & 23.2 & 0.874 \\
\hline
\end{tabular}

${ }^{a}$ Not all participants with methylation data $(n=552)$ had information for each population characteristic listed. Missing data did not exceed $2.4 \%$

${ }^{b}$ Underwent post-secondary education

'Independently unable to complete two items on both or either of the IADL and ADL scales

${ }^{\mathrm{d}}$ Hypertension: resting blood pressure $\geq 160 / 95 \mathrm{mmHg}$

eIschemic disease: History of angina pectoris, myocardial infarction, stroke, cardiovascular surgery and/or arteritis

${ }^{\mathrm{f}}$ Comorbidities: Ischemic or chronic (high blood pressure, high cholesterol, diabetes, thyroid disease, asthma) disease, or recent cancer (diagnosed within the last 2 years)

'MMSE: Mini-Mental State Examination

${ }^{\mathrm{h}} \mathrm{Chi}$-squared tests were used to assess p-value for all variables except age, where a t-test was used 
D Lam et al

Table 2. Potential associations between angiotensin converting enzyme (ACE) genotype and DNA methylation

\begin{tabular}{|c|c|c|c|c|c|}
\hline \multirow{2}{*}{$\begin{array}{l}\text { Polymorphism } \\
r s 4291\end{array}$} & \multirow{2}{*}{$\begin{array}{l}\text { CpG unit } \\
10.11 .12\end{array}$} & \multicolumn{3}{|c|}{ Methylation $^{\mathrm{a}}(\%)$} & \multirow{2}{*}{$\frac{p \text {-value }}{0.041}$} \\
\hline & & $\mathrm{AA}(7.72)$ & AT (7.72) & TT (7.04) & \\
\hline \multirow[t]{4}{*}{$r s 4295$} & 2 & $\mathrm{CC}(0.59)$ & CG (0.57) & GG (0.81) & 0.137 \\
\hline & 14 & $\mathrm{CC}(7.06)$ & CG (7.82) & GG (8.04) & 0.114 \\
\hline & 15.16 & $\mathrm{CC}(6.11)$ & CG (5.45) & GG (5.25) & 0.086 \\
\hline & 28.29 .30 & $\mathrm{CC}(5.20)$ & CG (4.86) & GG (4.27) & 0.146 \\
\hline \multirow[t]{2}{*}{$r s 4311$} & 14 & TT (8.11) & $\mathrm{TC}(7.65)$ & $\mathrm{CC}(6.78)$ & 0.081 \\
\hline & 15.16 & TT (5.45) & $\mathrm{TC}(5.48)$ & $\mathrm{CC}(6.24)$ & 0.102 \\
\hline$r s 4333$ & 28.29 .30 & TT (4.45) & $\mathrm{TC}(5.25)$ & CC (4.84) & 0.020 \\
\hline \multirow[t]{2}{*}{$r s 4343$} & 14 & GG (8.27) & GA (7.75) & AA (7.59) & 0.090 \\
\hline & 26 & GG $(0.28)$ & GA $(0.21)$ & AA $(0.31)$ & 0.079 \\
\hline$r s 4351$ & 27 & GG (1.12) & GA (1.05) & AA (1.43) & 0.136 \\
\hline
\end{tabular}

${ }^{a}$ Mean methylation presented as geometric mean

${ }^{\mathrm{b}}$ one-way ANOVAs were used to calculate $\mathrm{p}$-values and only those with $\mathrm{p}$-value $<0.15$ are shown 
D Lam et al

\section{Supplementary Material}

DNA methylation and genetic variation of the Angiotensin converting enzyme $(A C E)$ in depression

Dilys Lam, BSc (Hons); Marie-Laure Ancelin, PhD; Karen Ritchie, PhD; Richard Saffery, PhD; Joanne Ryan, $\mathrm{PhD}$

\section{Table of Contents}

Table S1. Cycling conditions for PCR amplification

Table S2. Individual CpG units assayed and analysed in this study

Table S3. Association between $A C E$ methylation and depression status

Table S4. Prevalence of $A C E$ genotypes in the study population according to depression status

Figure S1. The sequence of the $356 \mathrm{bp} A C E$ promoter assay 
D Lam et al

Table S1. Cycling conditions for PCR amplification

\begin{tabular}{llll}
\hline Step & Cycles & Temperature $\left({ }^{\circ} \mathrm{C}\right)$ & Time \\
\hline 1 & 1 & 95 & $10 \mathrm{~min}$ \\
& & 95 & $10 \mathrm{sec}$ \\
2 & 5 & 58 & $30 \mathrm{sec}$ \\
& & 72 & $2 \mathrm{~min}$ \\
& & 95 & $10 \mathrm{sec}$ \\
3 & 40 & 62 & $30 \mathrm{sec}$ \\
& & 72 & $1.5 \mathrm{~min}$ \\
4 & 1 & 72 & $7 \mathrm{~min}$ \\
5 & 1 & 4 & $\infty$ \\
\hline
\end{tabular}


D Lam et al

Table S2. Individual CpG units assayed and analysed in this study

\begin{tabular}{|c|c|c|c|c|c|c|c|}
\hline CpG unit & Position (chr17) & Included & $\begin{array}{l}\text { Reason for } \\
\text { exclusion }\end{array}$ & $n=$ & $\begin{array}{c}\text { Outliers } \\
\text { excluded (n) }\end{array}$ & $\begin{array}{c}\text { Mean } \\
\text { methylation }(\%)\end{array}$ & SD \\
\hline 1 & 63476818 & Yes & & 526 & 18 & 0.93 & 1.09 \\
\hline 2 & 63476807 & Yes & & 550 & 17 & 0.56 & 0.67 \\
\hline 3 & 63476798 & Yes & & 473 & 9 & 0.87 & 1.20 \\
\hline \multirow[t]{2}{*}{ 4.5.6.7 } & 63476785 & & & & & & \\
\hline & $\begin{array}{l}63476781 \\
63476777 \\
63476775\end{array}$ & Yes & & 542 & 5 & 2.75 & 1.19 \\
\hline 8.9 & $\begin{array}{l}63476767 \\
63476763\end{array}$ & Yes & & 449 & 5 & 7.51 & 3.57 \\
\hline 10.11 .12 & $\begin{array}{l}63476745 \\
63476738 \\
63476733\end{array}$ & Yes & & 525 & 5 & 7.61 & 2.18 \\
\hline 13 & 63476719 & Yes & & 414 & 12 & 8.00 & 6.79 \\
\hline 14 & 63476711 & Yes & & 505 & 16 & 7.89 & 2.80 \\
\hline 15.16 & $\begin{array}{l}63476701 \\
63476695\end{array}$ & Yes & & 533 & 15 & 5.53 & 1.94 \\
\hline 17 & 63476681 & Yes & & 532 & 17 & 3.16 & 1.66 \\
\hline 18 & 63476662 & Yes & & 545 & 19 & 2.44 & 1.71 \\
\hline 19.20.21.22.23 & $\begin{array}{l}63476656 \\
63476653 \\
63476649 \\
63476645 \\
63476642\end{array}$ & No & $<50 \%$ data & NA & NA & NA & NA \\
\hline 24.25 & $\begin{array}{l}63476626 \\
63476616\end{array}$ & No & $<50 \%$ data & NA & NA & NA & NA \\
\hline 26 & 63476593 & Yes & & 532 & 33 & 0.25 & 0.42 \\
\hline 27 & 63476586 & Yes & & 547 & 19 & 1.17 & 1.13 \\
\hline \multirow[t]{2}{*}{28.29 .30} & 63476580 & & & & & & \\
\hline & $\begin{array}{l}63476577 \\
63476570\end{array}$ & Yes & & 514 & 20 & 4.92 & 2.34 \\
\hline 31 & 63476553 & Yes & & 543 & 20 & 1.33 & 1.12 \\
\hline 32 & 63476533 & Yes & & 537 & 22 & 0.97 & 0.99 \\
\hline
\end{tabular}


D Lam et al

Table S3. Association between $A C E$ methylation and depression status

\begin{tabular}{|c|c|c|c|c|c|c|}
\hline CpG unit & Depression & $\mathrm{n}$ & $\operatorname{Mean}^{\mathrm{a}}(\%)$ & Difference (\%) & $95 \% \mathrm{CI}$ & $p$-value ${ }^{b}$ \\
\hline \multirow[t]{2}{*}{1} & No & 369 & 0.89 & \multirow{2}{*}{0.13} & \multirow{2}{*}{$-0.08 ; 0.35$} & \multirow{2}{*}{0.346} \\
\hline & Yes & 157 & 1.02 & & & \\
\hline \multirow[t]{2}{*}{2} & No & 386 & 0.56 & \multirow{2}{*}{0.01} & \multirow{2}{*}{$-0.12 ; 0.13$} & \multirow{2}{*}{0.830} \\
\hline & Yes & 164 & 0.57 & & & \\
\hline \multirow[t]{2}{*}{3} & No & 334 & 0.87 & \multirow{2}{*}{0.01} & \multirow{2}{*}{$-0.23 ; 0.25$} & \multirow{2}{*}{0.774} \\
\hline & Yes & 139 & 0.88 & & & \\
\hline \multirow[t]{2}{*}{ 4.5.6.7 } & No & 380 & 2.74 & \multirow{2}{*}{0.04} & \multirow{2}{*}{$-0.19 ; 0.27$} & \multirow{2}{*}{0.741} \\
\hline & Yes & 162 & 2.78 & & & \\
\hline \multirow[t]{2}{*}{8.9} & No & 316 & 7.60 & \multirow{2}{*}{-0.30} & \multirow{2}{*}{$-1.01 ; 0.43$} & \multirow{2}{*}{0.562} \\
\hline & Yes & 133 & 7.30 & & & \\
\hline \multirow[t]{2}{*}{10.11 .12} & No & 370 & 7.64 & \multirow{2}{*}{-0.11} & \multirow{2}{*}{$-0.51 ; 0.29$} & \multirow{2}{*}{0.813} \\
\hline & Yes & 155 & 7.54 & & & \\
\hline \multirow[t]{2}{*}{13} & No & 284 & 8.25 & \multirow[b]{2}{*}{-0.78} & \multirow[b]{2}{*}{$-2.15 ; 0.59$} & \multirow[b]{2}{*}{0.252} \\
\hline & Yes & 130 & 7.47 & & & \\
\hline 14 & No & 356 & 7.84 & & & \\
\hline & Yes & 149 & 8.03 & 0.19 & $-0.34 ; 0.73$ & 0.443 \\
\hline 15.16 & No & 375 & 5.58 & & & \\
\hline & Yes & 158 & 5.39 & -0.19 & $-0.55 ; 0.16$ & 0.330 \\
\hline 17 & No & 373 & 3.15 & & & \\
\hline & Yes & 159 & 3.19 & 0.04 & $-0.27 ; 0.35$ & 0.431 \\
\hline 18 & No & 384 & 2.44 & & & \\
\hline & Yes & 161 & 2.46 & 0.02 & $-0.31 ; 0.35$ & 0.743 \\
\hline 26 & No & 373 & 0.26 & & & \\
\hline & Yes & 159 & 0.24 & -0.02 & $-0.09 ; 0.05$ & 0.616 \\
\hline 27 & No & 384 & 1.12 & & & \\
\hline & Yes & 163 & 1.30 & 0.18 & $-0.03 ; 0.40$ & 0.229 \\
\hline 28.29 .30 & No & 366 & 4.91 & $00 ?$ & 041040 & 060 \\
\hline & Yes & 148 & 4.94 & 0.03 & $-0.41 ; 0.48$ & 0.626 \\
\hline 31 & No & 382 & 1.32 & & & \\
\hline & Yes & 161 & 1.37 & 0.05 & $-0.15 ; 0.27$ & 0.752 \\
\hline 32 & No & 377 & 0.99 & & & 0714 \\
\hline 32 & Yes & 160 & 0.92 & -0.07 & $-0.25 ; 0.11$ & 0.714 \\
\hline & No & 224 & 3.53 & & & \\
\hline Mean & Yes & 104 & 3.43 & -0.10 & $-0.23 ; 0.03$ & 0.941 \\
\hline
\end{tabular}

${ }^{a}$ Mean methylation presented as geometric mean

${ }^{\mathrm{b}} \mathrm{T}$-tests were used to calculate $\mathrm{p}$-values 


\begin{tabular}{|c|c|c|c|}
\hline SNP and genotype & No Depression (\%) & Depression(\%) & $p$-value ${ }^{\mathrm{a}}$ \\
\hline \multicolumn{4}{|l|}{$r s 1800764(\mathrm{n}=235)$} \\
\hline $\mathrm{TT}$ & 25.3 & 39.3 & \multirow{3}{*}{0.065} \\
\hline $\mathrm{TC}$ & 47.1 & 44.3 & \\
\hline $\mathrm{CC}$ & 27.6 & 16.4 & \\
\hline \multicolumn{4}{|l|}{$r s 4291(\mathrm{n}=552)$} \\
\hline AA & 32.2 & 39.0 & \multirow{3}{*}{0.222} \\
\hline AT & 50.8 & 48.2 & \\
\hline $\mathrm{TT}$ & 17.0 & 12.8 & \\
\hline \multicolumn{4}{|l|}{$r s 4295(\mathrm{n}=241)$} \\
\hline $\mathrm{CC}$ & 29.8 & 41.3 & \multirow{3}{*}{0.142} \\
\hline $\mathrm{CG}$ & 50.5 & 47.6 & \\
\hline GG & 19.7 & 11.1 & \\
\hline \multicolumn{4}{|l|}{$r s 4311(\mathrm{n}=240)$} \\
\hline TT & 33.9 & 20.6 & \multirow{3}{*}{0.075} \\
\hline $\mathrm{TC}$ & 49.2 & 52.4 & \\
\hline $\mathrm{CC}$ & 16.9 & 27.0 & \\
\hline \multicolumn{4}{|l|}{$r s 4333(\mathrm{n}=235)$} \\
\hline TT & 37.8 & 22.2 & \multirow{3}{*}{0.025} \\
\hline $\mathrm{TC}$ & 46.5 & 49.2 & \\
\hline $\mathrm{CC}$ & 15.7 & 28.6 & \\
\hline \multicolumn{4}{|l|}{$r s 4343(\mathrm{n}=552)$} \\
\hline GG & 35.3 & 26.2 & \multirow{3}{*}{0.114} \\
\hline GA & 46.7 & 53.1 & \\
\hline AA & 18.0 & 20.7 & \\
\hline \multicolumn{4}{|l|}{$r s 4351(\mathrm{n}=234)$} \\
\hline GG & 36.8 & 20.6 & \multirow{3}{*}{0.020} \\
\hline GA & 48.6 & 52.4 & \\
\hline AA & 14.6 & 27.0 & \\
\hline
\end{tabular}

Table S4. Prevalence of $A C E$ genotypes in the study population according to depression status ${ }^{a}$ Chi-squared tests were used to calculate p-value 
CAGAGGAAGCTGGAGAAAGGGCCTCCTCTCTTTAGAAGATGGGGACC1C $\underline{\mathbf{G}}$ GCAGTTTGC ${ }^{2} \mathbf{C G G A A C A C C}^{3} \mathbf{C G A G C C T G C C C A C} \mathbf{C G T G}^{5} \mathbf{C G G C}^{6} \mathbf{C G}^{7} \mathbf{C G C}$



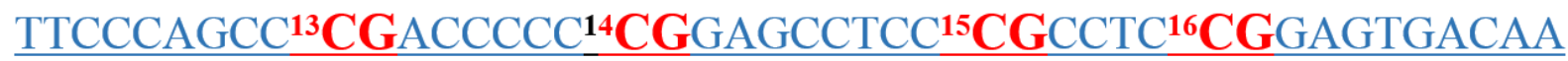

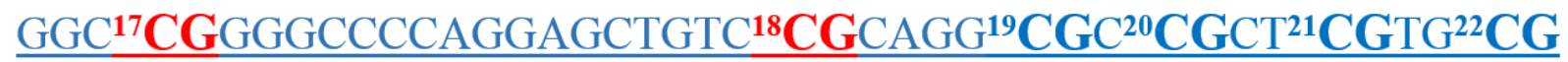
$\mathrm{G}^{23}$ CGGGGATGGGGCTGAT ${ }^{24}$ CGGGCCTGGC $^{25}$ CGGCTTCTTCACCAGGCCA

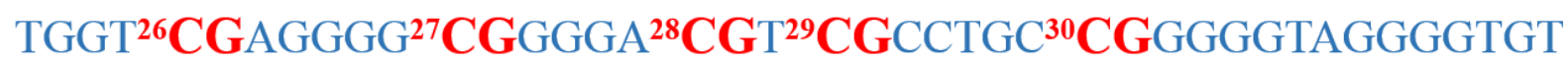



Figure S1. The sequence of the 356bp ACE promoter assay. CpG sites are bolded, with all studied CpG sites denoted in red. Primer sequences are shaded. The region covered in a previous study, Zill et al. 2012 , is underlined. 
D Lam et al

\section{Figure Legends}

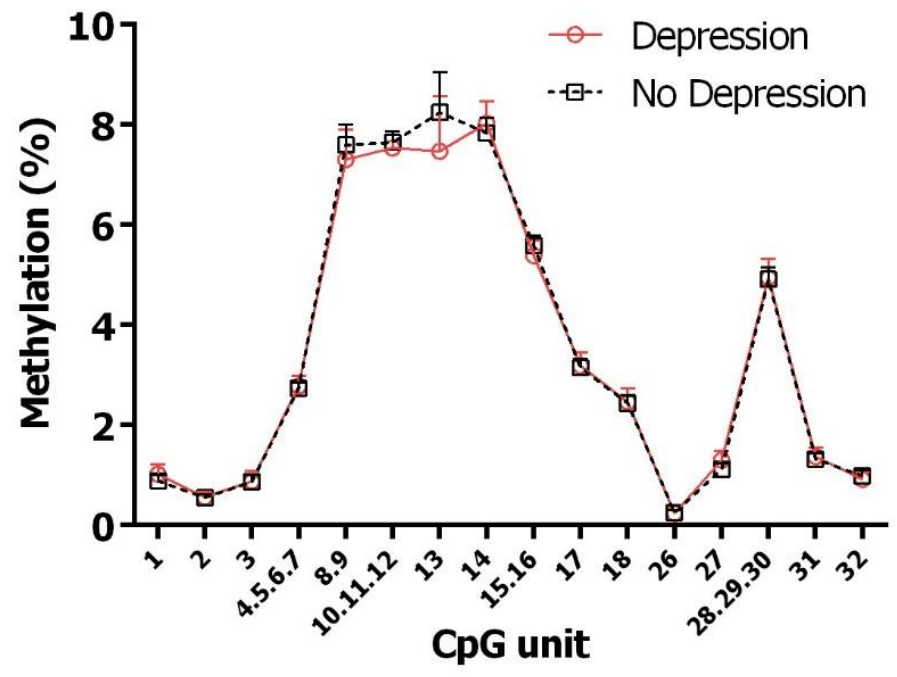

Figure 1. Methylation differences between depressed and non-depressed individuals at each $\mathrm{CpG}$ unit. Data is presented as the geometric mean $\pm 95 \%$ confidence interval (CI). T-tests were used to calculate p-values. 
(a)

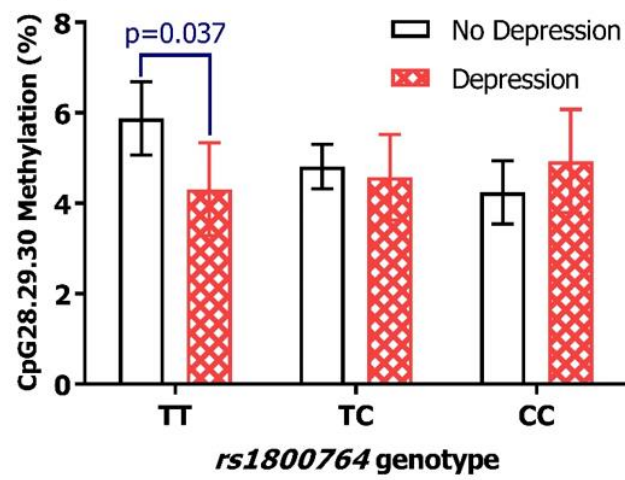

(c)

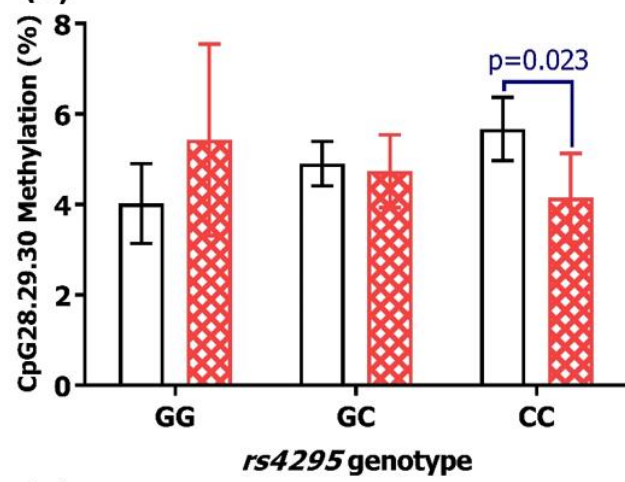

(e)

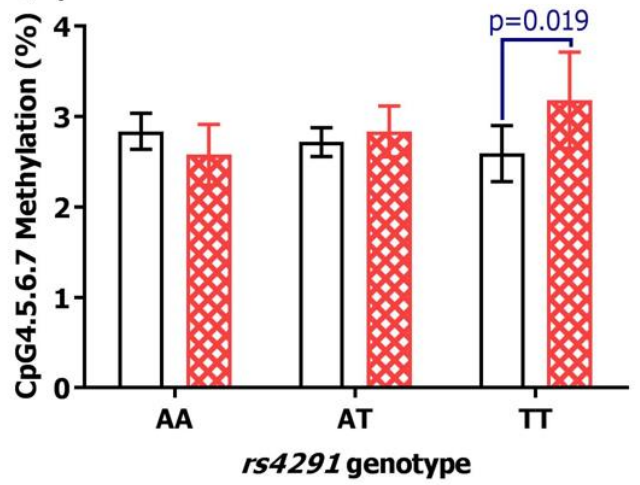

(g)

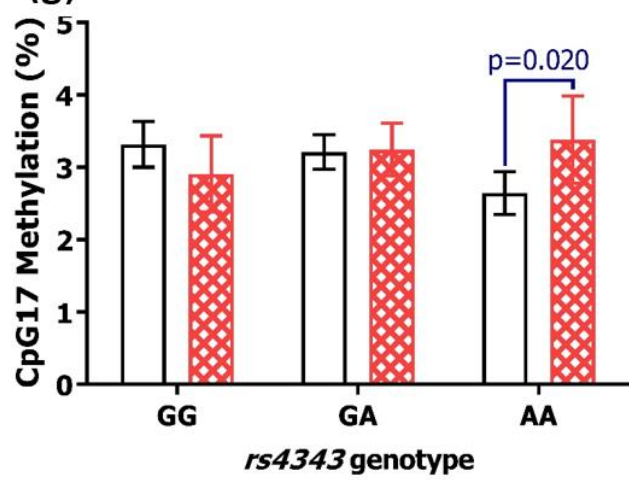

(b)

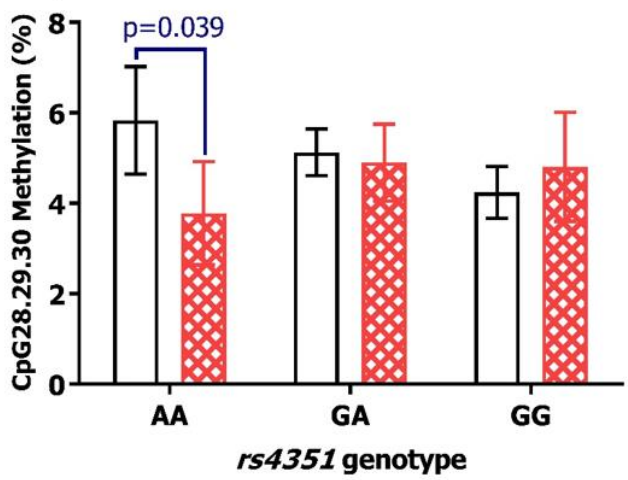

(d)

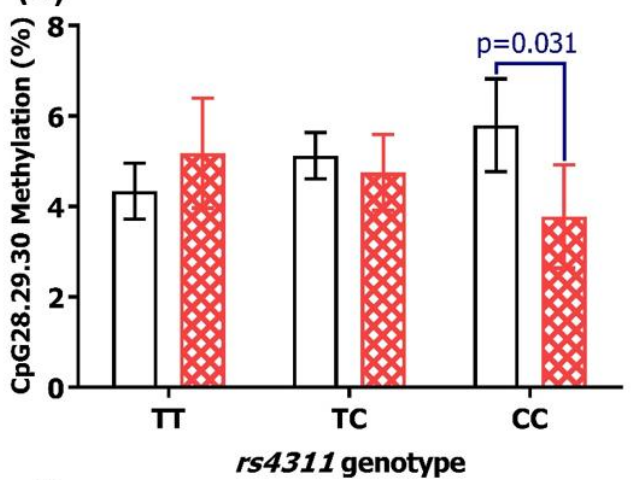

(f)

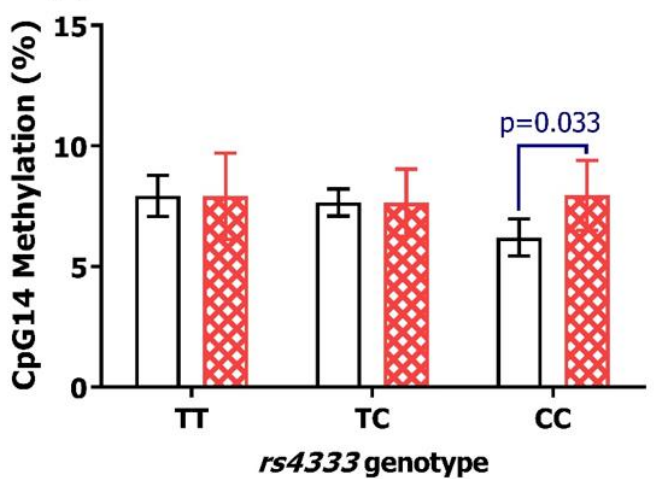

Figure 2. Differences in methylation levels at $\mathrm{CpG}$ units according to depression status, stratified by angiotensin converting enzyme ( $A C E$ ) genotypes: (a) $\mathrm{CpG} 28.29 .30$ rs 1800764 ( $\mathrm{n}=219)$; (b) $\mathrm{CpG}$ 28.29.30 rs4351 (n=219); (c) CpG 28.29.30 rs4295 (n=225); (d) CpG 28.29.30 rs4311 ( $\mathrm{n}=224) ;(\mathrm{e})$ CpG 4.5.6.7 (rs4291, n=542); (f) CpG 14 (rs4333, n=212); (g) CpG 17 (rs4343, n=532). Data presented as the geometric mean methylation $\pm 95 \% \mathrm{CI}$. T-tests were used to calculate p-values, with significant associations at $\mathrm{p}<0.05$ indicated in the figure. 


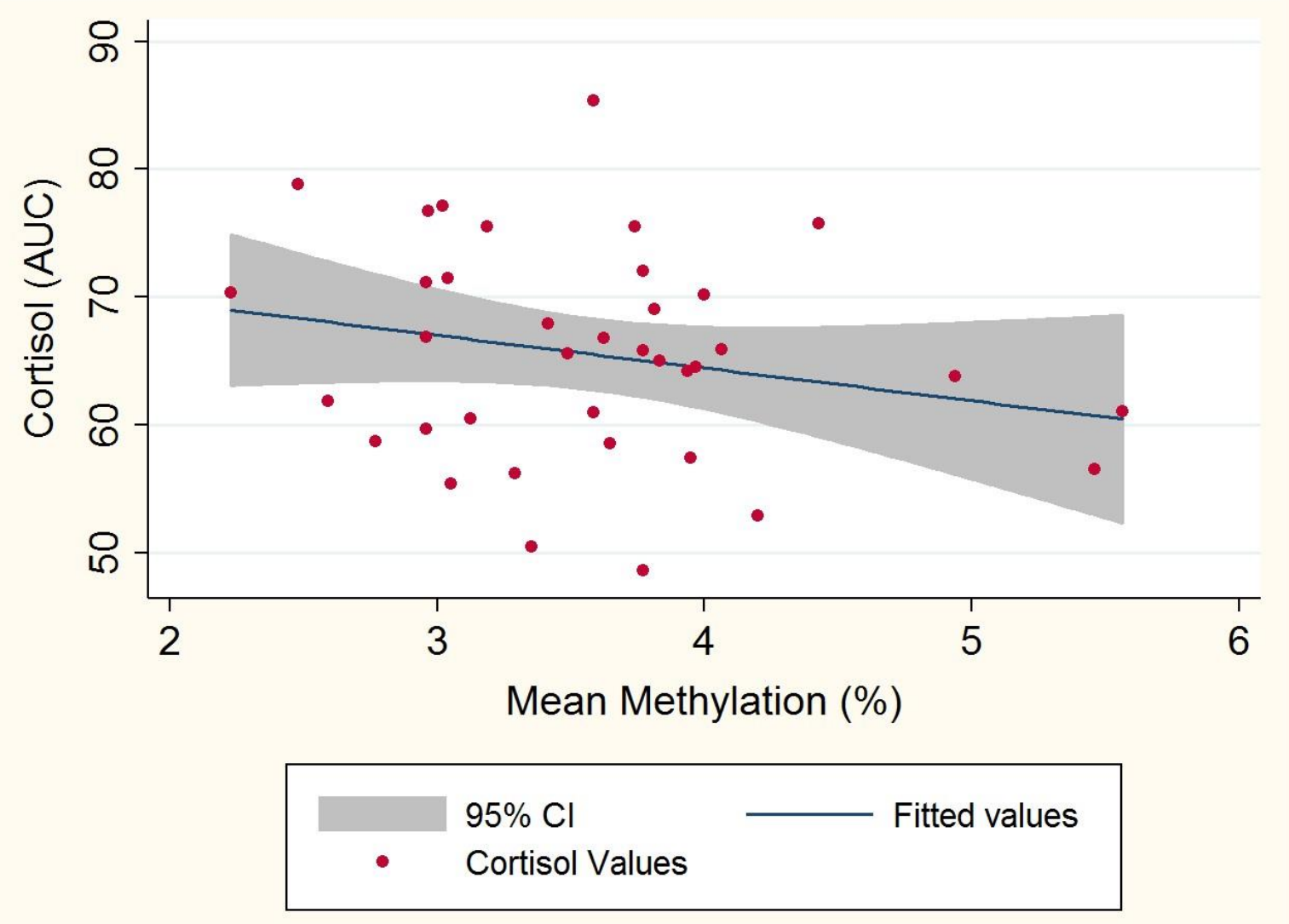

Figure 3. Correlation between baseline cortisol AUC levels and average methylation $(r=-0.336$, $\mathrm{p}=0.042$ ). The blue line represents the line of best fit, and the shaded area is the associated $95 \% \mathrm{CI}$. 